\title{
Intrapleural r-tPA in Association with Low-Molecular Heparin May Cause Massive Hemothorax Resulting in Hypovolemia
}

\author{
Stavros Anevlavis Kostas Archontogeorgis Argyris Tzouvelekis \\ George Kouliatsis Sofia Pozova loannis Bougioukas Demosthenes Bouros \\ Marios E. Froudarakis \\ Department of Pneumonology, and CardioThoracic Surgery Medical School, Democritus University of Thrace, \\ Alexandroupolis, Greece
}

\section{Established Facts}

- $\quad \mathrm{r}$-tPA is under investigation as an intrapleural fibrinolytic in pleural infections.

\section{Novel Insights}

- r-tPA associated with either therapeutic or prophylactic low-molecular weight heparin may cause massive intrapleural hemorrage with hypovolemia.

\section{Key Words}

Complicated parapneumonic effusion · Empyema •

Fibrinolytics · Hemothorax • Hypovolemia • Low-molecular weight heparin - Pleural infection - Recombinant tissue plasminogen activator

\footnotetext{
Abstract

The use of intrapleural instillation of recombinant tissue plasminogen activator ( $r$-tPA) in the treatment of pleural infection may increase pleural fluid drainage associated with a clinical and imaging improvement, leading to a faster reso-
}

lution. The use of r-tPA is generally well tolerated. Here we report 2 cases of massive pleural hemorrhage resulting in life-threatening hypovolemia, in 2 patients treated with intrapleural r-tPA for a pleural infection, who were simultaneously receiving systemic anticoagulation (1 therapeutic, the second prophylactic) with low-molecular weight heparin. It appears that the decision of treating pleural infection with r-tPA in patients receiving therapeutic or prophylactic systemic anticoagulation must be well balanced and in case of association of these compounds, close monitoring is necessary.

Copyright $\odot 2010$ S. Karger AG, Basel

\section{KARGER}

Fax +4161306 1234

E-Mail karger@karger.ch

www.karger.com
(C) 2010 S. Karger AG, Basel

0025-7931/11/0816-0513\$38.00/0

Accessible online at:

www.karger.com/res
Stavros Anevlavis, $\mathrm{MD}, \mathrm{PhD}$

Department of Pneumonology

University Hospital of Alexandroupolis

GR-68100 Alexandroupolis (Greece)

Tel./Fax +30 255107 5096, E-Mail anevlavis@yahoo.com 


\section{Introduction}

The use of fibrinolytics in the treatment of complicated parapneumonic effusions (CPE) was first described in the 1950s [1]. Efficacy of classic fibrinolytics (urokinase and streptokinase) in CPE is a subject of debate [2]. The systemic side effects of streptokinase [3] (delayed hypersensitivity reactions and antibodies development) and the risk of viral disease transmission related to urokinase [4], has led to the use of recombinant tissue plasminogen activator ( $\mathrm{r}-\mathrm{tPA}$ ) as a more appropriate therapeutic agent [5].

Studies of intrapleural instillation of r-tPA in the treatment of CPE demonstrated an increase of pleural fluid drainage. This increase was associated with improvement of clinical symptoms and radiologic findings [5]. In most of the cases the use of $\mathrm{r}$-tPA was well tolerated. Even though most common adverse effects included chest pain and local bleeding at the chest tube insertion site, cases of pleural hemorrhage were described in patients receiving simultaneously systemic anticoagulation in a therapeutic range [6]. We will report 2 cases of massive pleural hemorrhage resulting in life-threatening hypovolemia, in 2 patients treated with intrapleural r-tPA for a CPE who were simultaneously receiving systemic anticoagulation (1 therapeutic, the second prophylactic) with low-molecular weight heparin.

\section{Case Report}

\section{Case 1}

A 54-year-old male patient was admitted to a nearby hospital with pleuritic pain of the right hemithorax that had begun 30 days before his admission, fever and dyspnea of sudden onset. A chest $\mathrm{X}$-ray demonstrated a pleural effusion of the right hemithorax. An antibiotic therapy was initiated and the patient was transferred to our institution for further evaluation and management of his pleural effusion.

From his medical history arterial hypertension and chronic alcohol consumption were established. The patient was a smoker (60 pack years). On admission the patient was dehydrated and had fever. On physical examination a respiratory rate of 18 breaths per minute, a reduction of the respiratory sounds on his right lung and a palpable hepatomegaly were noted. His arterial blood gasses showed $\mathrm{PO}_{2}=57 \mathrm{~mm} \mathrm{Hg}, \mathrm{PCO}_{2}=40 \mathrm{~mm} \mathrm{Hg}, \mathrm{pH} 7.40$, while receiving $2 \mathrm{l} / \mathrm{min}$ by nasal canula. His blood test revealed white blood cells $=18,000 / \mathrm{mm}^{3}$ with $79.2 \%$ neutrophils, hemoglobin $=$ $15.4 \mathrm{~g} / \mathrm{dl}$ and CRP $=10.96 \mathrm{mg} / \mathrm{dl}$. His coagulation tests were $\mathrm{aPTT}=30.30 \mathrm{~s}, \mathrm{INR}=1.49$ with D-Dimers $=651.44 \mathrm{ng} / \mathrm{ml}$. An ultrasound of the right hemithorax determined a loculated pleural effusion. A spiral CT scan demonstrated an extensive pleural effusion of the right hemithorax with initial loculation and a right lower lobe consolidation with air-bronchogram. A peripheral em- bolus at the lower branch of the left pulmonary artery and an atelectasis of the lingula were also verified. Pleural fluid thoracocentesis showed cell count $=24,000$ cells, with $98 \%$ neutrophils, $2 \%$ lymphocytes, $\mathrm{LDH}=502 \mathrm{U} / \mathrm{l}$, total protein $=4.9 \mathrm{~g} / \mathrm{dl}$ and $\mathrm{pH} 7.0$.

Pleural fluid cultures for aerobic, anaerobic bacteria, mycobacteria and cytological exam were negative. Intravenous antibiotic treatment was started (ceftriaxone, ciprofloxacin, clindamycin) and a closed intercostal drainage with a chest tube attached to a water-sealed system was placed to the right hemithorax draining immediately $700 \mathrm{~cm}^{3}$ of pleural fluid. An anticoagulation therapy with a therapeutic dose of low-molecular weight heparin (tinzaparin 14,000 IU) was initiated. During the first $24 \mathrm{~h}$, another $70 \mathrm{~cm}^{3}$ of pleural fluid were drained and the first dose of r-tPA ( $25 \mathrm{mg}$ of alteplase in $100 \mathrm{~cm}^{3}$ of $0.9 \%$ saline solution) was administered via the chest tube as previously reported [5]. After the first instillation, $640 \mathrm{~cm}^{3}$ of pleural fluid were drained in the next $24 \mathrm{~h}$, and a second and third instillation followed, once daily, draining in total $3,600 \mathrm{~cm}^{3}$ of pleural fluid.

After the third instillation, a change to the characteristics of the pleural fluid was noticed, with a switch from serous to serosanguinous fluid and a drop in the hemoglobin (to 9.8 from 15.4) within $24 \mathrm{~h}$, associated with clinical symptoms and signs of hypovolemia (tachycardia, drop of blood pressure, anxiety, discomfort). His coagulation profile was PT $15.1 \mathrm{~s}$, INR 1.38, aPTT $32.90 \mathrm{~s}$. Intrapleural instillation of r-tPA was interrupted. The patient was transfused until a rise in the hemoglobin was obtained. Treatment with low-molecular weight heparin was suspended and because the patient still presented high fever, ceftriaxone was interrupted and substituted by linezolid. Since no sources of active hemorrhage were verified, except a hematoma developed around the tube insertion site, an intrapleural hemorrhage was suspected. A new chest CT scan was performed, demonstrating a large pleural effusion with multiple loculations at the right hemithorax. The first chest tube was then removed and a new one was placed in the largest loculation. Over the next $24 \mathrm{~h}$ a total of 60 $\mathrm{cm}^{3}$ of sanguinous fluid were drained. A surgical consultant was asked and the patient was transferred to the thoracic surgery department for further treatment of suspected hemothorax. The patient underwent thoracotomy and decortication of the middle and right lower lobes and a large amount of blood and blood clots were found in the pleural space, but no site of active bleeding was established. After 6 days of convalescence the patient had improved clinically and was discharged in a generally good condition.

Case 2

A 78-year-old male non-smoker was admitted to our hospital for dyspnea, which had begun 4 days before his admission, and pleural pain on his right hemithorax. From his medical history we noted arterial hypertension and diabetic chronic renal failure (stage III, eGFR $=50 \mathrm{ml} / \mathrm{min}$ ). The patient was receiving prophylactic doses of subcutaneous low-molecular weight heparin (tinzaparin 3,500 IU). On physical examination the patient was tachypnoic (respiratory rate of 18 breaths per minute). Crackles with reduction of the respiratory sounds on the right base were noted. Arterial blood gases in room air showed $\mathrm{PO}_{2}=54 \mathrm{~mm} \mathrm{Hg}$, $\mathrm{PCO}_{2}=43 \mathrm{~mm} \mathrm{Hg}, \mathrm{pH} 7.47$. His chest X-ray showed a right lower lobe consolidation and a pleural effusion. His blood test revealed: $\mathrm{WBC}=13,640 / \mathrm{mm}^{3}$ with $71 \%$ neutrophils, hemoglobin $=16.0 \mathrm{~g} /$ $\mathrm{dl}, \mathrm{CRP}=12.73 \mathrm{mg} / \mathrm{dl}$. His coagulation tests were: $\mathrm{aPTT}=24.90 \mathrm{~s}$, 
INR $=1.30$. A chest ultrasound was performed, demonstrating a free-flowing right pleural effusion of approximate $50 \mathrm{ml}$. An antibiotic therapy with amoxicillin-clavulanate and ciprofloxacin was started.

At the seventh day of his hospitalization, the patient presented fever and a chest X-ray showed an increase of the pleural effusion. A new chest ultrasound was performed showing a large septated pleural effusion. A diagnostic thoracocentesis was performed and aliquots of pleural fluid were sent to chemical and microbiologic analysis. Pleural fluid cell count demonstrated 19,800 red blood cells, 1,140 white blood cells with $45 \%$ neutrophils and a hematocrit under 15, an LDH $=326 \mathrm{U} / \mathrm{l}$ and total protein $=4.4 \mathrm{~g} / \mathrm{dl}$. Pleural fluid cultures for aerobic, anaerobic bacteria, mycobacteria and cytology were negative. Chest tube drainage was placed to the right hemithorax draining immediately $600 \mathrm{~cm}^{3}$ of pleural fluid. During the first $24 \mathrm{~h}$, another $60 \mathrm{~cm}^{3}$ of pleural fluid were drained and the first dose of r-tPA ( $25 \mathrm{mg}$ of alteplase in $100 \mathrm{~cm}^{3}$ of $0.9 \%$ saline solution) was administered via the chest tube as previously reported [5]. Another 3 instillations of r-tPA via the chest tube followed, draining a total of $5,040 \mathrm{ml}$ of yellow-tainted pleural fluid. After the fourth instillation a switch from serous to sanguineous change of the pleural fluid was noticed. The sample taken from pleural fluid showed a hematocrit of $51 \%$. A decrease in the patient's plasma hemoglobin was also noted (hemoglobin = $7.1 \mathrm{~g} / \mathrm{dl}$ ). His coagulation tests were: $\mathrm{aPTT}=20.50 \mathrm{~s}, \mathrm{INR}=1.78$. Intrapleural instillation of r-tPA was interrupted because of suspected hemothorax resulting in life-threatening hypovolemia. The patient was transfused until a rise of the hemoglobin was obtained. A chest CT scan was performed evidencing a large pleural effusion with multiple septations and a right lower lobe atelectasis. The chest tube was left in place and 2 days later a drop in the pleural fluid hematocrit was noted. Antibiotic treatment continued until the patient's temperature and white blood cell count returned to normal. A total of 7,160 $\mathrm{ml}$ of pleural fluid were drained before the chest tube was removed and the patient was dismissed in good condition.

\section{Discussion}

There is only 1 study that refers to the risk of intrapleural hemorrhage related to the simultaneous use of r-tPA and a therapeutic dose of systemic anticoagulation in adults with CPE. These 2 cases uniquely illustrate the importance of intrapleural hemorrhage resulting in hypovolemia, and the fact that this can happen either with therapeutic or prophylactic low-molecular weight heparin.

The therapeutic action of $\mathrm{r}$-tPA in the CPE is probably related to the pathogenesis of fibrin deposition in exudative pleural effusions, which includes an imbalance of coagulant and fibrinolytic activity secondary to a decreased level of endogenous r-tPA in the pleural fluid, and to the inhibition of plasminogen and plasmin by plasminogen activator inhibitors 1 and 2 and by other mediators $[7,8]$. $\mathrm{r}$-tPA acts by breaking the fibrin loculations allowing easier drainage of the pleural fluid.

Intrapleural r-tPA and LMW Heparin in Hemothorax
In a study conducted by Gervais et al. [6], 66 patients with CPE were treated with intrapleural $r$-tPA. From these patients 12 received systemic anticoagulation at a therapeutic dosage and 38 received prophylactic subcutaneous heparin. Major pleural hemorrhages were observed in 4 of the patients who received systemic anticoagulation in a therapeutic range ( 2 received unfractioned heparin, 1 received low-molecular-weight heparin at a therapeutic dosage and 1 warfarin) with a rate of major hemorrhage of $33 \%$, while no hemorrhages were noted between those treated with a prophylactic dose of subcutaneous heparin. The risk of bleeding was statistically significant $(\mathrm{p}<$ 0.001 ) between patients who were receiving anticoagulation in a therapeutic range and those who received prophylactic dosages. Despite the bleeding, in 3 of 4 patients who bled, CPE was successfully drained and video-assisted thoracoscopic surgery was required in only 1 patient (75\% of success). Since no systemic hemorrhage was documented in any of the patients, the authors assumed that pleural bleeding was caused by a synergic action of r-tPA and systemic anticoagulation, which had a local effect on the pleura [6].

It seems that urokinase or streptokinase used as intrapleural agents in pleural infection have fewer hemorrhagic complications [9-11]. Davies et al. [9] examined the systemic fibrinolytic activity of streptokinase and noted no significant systemic effects from the intrapleural administration. Bouros et al. [10] compared streptokinase with urokinase and found similar efficacies and no increase in adverse reactions other than fevers in $8 \%$ of the streptokinase arm. In the MIST1 study [11], the reported hemorrhagic side effects (local, pleural, and systemic) were $3 \%$ for both the streptokinase and the placebo groups. There is no report mentioning whether patients with intrapleural bleeding were under simultaneous anticoagulation therapy.

In our first case, a therapeutic dosage of low-molecular weight heparin was used due to underlying pulmonary embolism. Our patient developed a massive hemothorax after the third instillation of r-tPA and had to be transfused in order to correct his hypovolemia. Due to the presence of a large amount of blood in the pleural cavity he underwent thoracotomy and decortication. The reason for pleural bleeding is a probable synergic action of r-tPA and the systemic anticoagulation, which had a local effect on the pleura.

In our second case, our patient developed a massive hemothorax after the fourth instillation of r-tPA. The patient was on a prophylactic dosage of low-molecular weight heparin. Although the patient developed hemo-

Respiration 2011;81:513-516 
thorax and life-threatening hypovolemia, he was treated with blood transfusions and there was no need for surgical treatment as in our first case. To our knowledge, these are the first reported cases of massive hemothorax after instillation of r-tPA for complicated parapneumonic effusion with hypovolemia associated with either therapeutic or prophylactic doses of low-molecular weight heparin.

It appears that the decision to treat CPE with r-tPA in patients who receive a therapeutic or prophylactic sys- temic anticoagulation with low-molecular weight heparin should be considered carefully. The use of r-tPA should be evaluated separately for each case and a rational weighing-up of the pros and cons should be done. Since there is no way to predict a possible massive intrapleural hemorrhage due to the synergic action of those 2 compounds, close monitoring is necessary to prevent lifethreatening hypovolemia, as in our cases.

\section{References}

$>1$ Tillett WS, Sherry S, Read CT: The use of streptokinase-streptodornase in the treatment of postneumonic empyema. J Thorac Surg 1951;21:275-297.

$\checkmark 2$ Koegelenberg CF, Diacon AH, Bolliger CT: Parapneumonic pleural effusion and empyema. Respiration 2008;75:241-250.

$\checkmark 3$ Aye RW, Froese DP, Hill LD: Use of purified streptokinase in empyema and hemothorax. Am J Surg 1991;161:560-562.

4 Hartnell GG, Gates J: The case of Abbokinase and the FDA: the events leading to the suspension of Abbokinase supplies in the United States. J Vasc Interv Radiol 2000;11: 841-847.
5 Froudarakis ME, Kouliatsis G, Steiropoulos P, Anevlavis S, Pataka A, Popidou M, et al: Recombinant tissue plasminogen activator in the treatment of pleural infections in adults. Respir Med 2008;102:1694-1700.

6 Gervais DA, Levis DA, Hahn PF, Uppot RN, Arellano RS, Mueller PR: Adjunctive intrapleural tissue plasminogen activator administered via chest tubes placed with imaging guidance: effectiveness and risk for hemorrhage. Radiology 2008;246:956-963.

7 Idell S, Girard W, Koenig KB, McLarty J, Fair DS: Abnormalities of pathways of fibrin turnover in the human pleural space. Am Rev Respir Dis 1991;144:187-194.

$>8$ Philip-Joet F, Alessi MC, Philip-Joet C, Aillaud M, Barriere JR, Arnaud A, et al: Fibrinolytic and inflammatory processes in pleural effusions. Eur Respir J 1995;8:1352-1356.
9 Davies CW, Lok S, Davies RJ: The systemic fibrinolytic activity of intrapleural streptokinase. Am J Respir Crit Care Med 1998;157: 328-330.

10 Bouros D, Schiza S, Patsourakis G, Chalkiadakis G, Panagou P, Siafakas NM: Intrapleural streptokinase versus urokinase in the treatment of complicated parapneumonic effusions: a prospective, double-blind study. Am J Respir Crit Care Med 1997;155:291295.

11 Maskell NA, Davies CW, Nunn AJ, Hedley EL, Gleeson FV, Miller R, et al: UK Controlled trial of intrapleural streptokinase for pleural infection. N Engl J Med 2005;352: 865-874. 